these changes varied simply with loss of sleep. This, however, did affect choice reaction time in which the ability to maintain a constant level of performance over blocks of trials was impaired. Wilkinson found the same effects after deprivation of sleep, provided the task exceeded five minutes; compensation was possible in tasks of up to five minutes' duration. ${ }^{\text {is }}$ The need to sustain performance for longer than five minutes, which also applied to our study, may have a bearing on the results of Poulton $e t a l$, who concluded from a study of 30 junior doctors who had lost between three and eight hours' sleep that the doctors could compensate on the basis of tasks of less than five minutes' duration.

Though mood ratings do not have the same objectivity as the cognitive measures, the values obtained here corroborate earlier results in which the same mood schedule was examined in a study of the effects of 24 hours' deprivation of sleep in volunteers. ${ }^{12}$ In our study the house officers showed significant deleterious changes in all the mood scales after night duty.

Laboratory evidence of the adverse effects of night duty may nevertheless underestimate their implications for the ward environment and their consequences for the doctor-patient relationship. As in previous studies the length of testing, here a 35 minute session, was necessarily curtailed to encourage cooperation with testing. Even so, many doctors were unwilling to participate. If the test sessions had been longer more complex inaccuracies in performance and cognitive functions may well have been manifested. The raised scores on the confusion-bewilderment scale suggest such a potential.
In conclusion the reduction in cognitive performance combined with the adverse changes in mood show less than desirable conditions for personal wellbeing and the practice of medicine. Superimposed night duty rosters may be a stress adversely affecting the welfare of both the doctor and the patient.

1 Social Services Committee. Medical education; with special reference to the mumber of docurs und the career structure in hospials. Session 1980-81. number of doctors and the career
London: HMSO, 1981. (No 31.)

2 Vailiant GE. Some psychologic vulnerabilities of physicians. N Engl f Med $1973 ; 287: 372-5$

3 Wilkinson RT, Tyler P, Varey C. Duty hours of young hospital doctors: effects on the quality of their work. Fournal of Occupational Psychology 1975;48 219-29.

4 Friedman RC, Kornfeld DS, Bigger TJ Jr. Psychological problems associated with sleep deprivation in interns. F Med Educ 1973;48:436-41.

5 Poulton E, Hunt G, Carpenter AL, Edwards R. The performance of junior hospital doctors following reduced sleep and long hours of work. Ergonomics 1981:21:279-95.

6 Asken MJ, Rahan DC. Resident performance and sleep deprivation. 7 Med Educ 1983;58:382-7.

Oswald I. Do we need sleep? BMA News Review. 1987:13(Oct): 16-8

7 Oswald I. Do we need sleep? BMA News Review. 1987;13(Oct):16-8. reduced sleep. Psychosonomic Science 1966;5:471-2.

9 Kugler B, Henley S. Lateral effects in the tactile modality in schizophrenia. In uruzelier J, Flor-Henry P, eds. Hemisphere asymmetry of function and
(a) Henles psychopathology. Amsterdam: Elsevier, 1979:475-90.

10 Gruzelier JH, Brow TD, Perry A, Rhonder J, Thomas M. Hypnotic susceptibility: a lateral predisposition and altered cerebral asymmetry under hypnosis. Int f Psychophysiol 1974;2:131-9.

11 McNair DN, Lorr M, Droppleman LF. Profile of mood states manual. San Diego: Educational and Industrial Testing Service, 1971

12 Wilkinson RT. Sleep deprivation. In: Edholm OG, Bacharach AL, eds. The physiology of human survival. New York: Academic Press, 1965:85-94.

13 Cutler $\mathrm{N}$. Cohen $\mathrm{H}$. The effects of one night's sleep loss on mood and memory in normal subjects. Compr Psychiatry 1974;20:61-6.

4 Webb WB, Agnew HW. The effects of a chronic limitation of sleep length. Psychophysiology 1974;11:265-74.

15 Kollar E, Slater G, Palmer J, Mandell R. Stress in subjects undergoing sleep deprivation. Psychosom Med 1964;28:101-3.

(Accepted 7 November 1988)

\title{
Lung immunoglobulins in the sudden infant death syndrome
}

\author{
Kevin D Forsyth, Sandy C Weeks, Lin Koh, John Skinner, John Bradley
}

\section{Flinders University of}

South Australia

Kevin D Forsyth, FRACP,

lecturer in paediatrics and

immunology

Sandy C Weeks, BSC, scientist, department of histopathology

John Skinner, FRCPA, associate professor, department of histopathology

John Bradley, FRCPA, associate professor, department of clinical immunology

Flinders Medical Centre, Adelaide, South Australia Lin Koh, BSC, scientist, department of clinical immunology

Correspondence to: $\mathrm{Dr}$ Kevin Forsyth, Department of Immunology, Institute of Child Health, University of London, London

WCIN 1EH

BrMed f 1989;298:23-6.

\section{Abstract}

The incidence of the sudden infant death syndrome parallels that of respiratory tract infections in the paediatric community. On the basis that the aetiology of the sudden infant death syndrome may lie in an unusual response to a trivial intercurrent respiratory infection a necropsy study was carried out investigating pulmonary immunoglobulins in 16 victims of the syndrome and a series of infants (controls) who had died of non-pulmonary causes. Compared with the controls victims of the sudden infant death syndrome had grossly raised concentrations of IgG, IgM, and to a less extent IgA in lung lavage samples. In addition, pulmonary interstitial and terminal airway cells expressing these immunoglobulins were identified far more often in victims than controls. The study failed to determine whether the increased immunoglobulin concentrations were a consequence of an unusual response to a trivial infection or an expression of otherwise altered immunological control in the respiratory tract.

Epidemiological evidence and the findings of this study suggest that the respiratory tract is the prime target organ in the sudden infant death syndrome.

\section{Introduction}

The sudden infant death syndrome is the main cause of mortality in the first year of life in developed countries. Despite extensive efforts, no unifying concept of pathophysiology can explain most cases. Analysis of epidemiological data shows that the syn- drome is more common in colder climates during the winter and that its incidence correlates with respiratory tract infections, particularly rates of admission to hospital for bronchiolitis. ${ }^{2}$ A highly significant correlation has been reported between the isolation of respiratory viruses in the general paediatric population and the incidence of the sudden infant death syndrome. ${ }^{3}$ Often victims of the syndrome have an upper respiratory tract infection in the week preceding death, ${ }^{+}$some $40-75 \%$ of victims having evidence of mild upper respiratory tract infection with various viruses. ${ }^{\varsigma}$ Hence an unusual response to a common viral pathogen is epidemiologically possible. Analysis of the immunological state of the lung may therefore help to answer whether immunological dysregulation is occurring in the sudden infant death syndrome.

The aim of this study was to measure concentrations of immunoglobulins IgG, IgA, and IgM in lung lavage samples from victims of the sudden infant death syndrome and compare them with values in controls. In addition, the presence of these immunoglobulins in cells within lung sections collected at necropsy were quantified and compared with controls.

\section{Subjects and methods}

All previously well infants who die suddenly and unexpectedly (presumptive sudden infant death syndrome) in South Australia come to necropsy at the Adelaide Children's Hospital by direction of the state coroner. We collected lung lavage samples and lung tissue from 16 such cases (mean age of victims $3 \cdot 8$ 
months, range 1-7). Using the same procedure we also collected lung lavage samples from eight controls (mean age 4.8 months, range 2-10) and lung tissue from four controls (mean age 5.3 months, range 3-9). The controls were previously well children who had died of acute, non-pulmonary causes. They came to necropsy because they had congenital abnormalities or had died as a result of an accident. Accident victims with pulmonary contusion were excluded. In all cases specimens were collected 12 to 24 hours after the presumed time of death. The results of cellular and virological studies have been reported. ${ }^{\circ}$

Lung lavage fluid immunoglobulin concentrationsImmunoglobulins IgG, IgA, and IgM were measured by a sensitive competitive inhibition enzyme immunoassay. ${ }^{7}$ Briefly, polystyrene tubes were used as the solid phase and coated with the appropriate pure immunoglobulin (rabbit antihuman IgG, IgA, or IgM; DAKO, Denmark). The lavage samples were diluted $50 \%$ and added to the solid phase together with purified antihuman IgG, IgA, or IgM coupled to horseradish peroxidase. 5-Aminosalicylic acid was used as the enzyme substrate and the absorbance measured at $474 \mathrm{~nm}$. In this assay, as the amount of solid phase immunoglobulin is limited, the amount of enzyme bound is inversely proportional to the concentration of immunoglobulin in the test sample. With this assay IgG is detectable down to $2.5 \mu \mathrm{g} / \mathrm{l}$, IgA down to $4 \cdot 2 \mu \mathrm{g} / \mathrm{l}$, and $\operatorname{IgM}$ down to $7 \cdot 2 \mu \mathrm{g} / \mathrm{l}$. There is undetectable cross reactivity among the immunoglobulin classes with the exception of purified $\operatorname{IgM}$, which cross reacted at $1.9 \%$ with the IgG enzyme immunoassay. ${ }^{7}$ For standardisation all results were expressed as $\mu \mathrm{g}$ immunoglobulin/mg total protein in the lavage sample. Total protein in $\mathrm{mg} / \mathrm{ml}$ was measured by the Lowry method. ${ }^{8}$

Immunostaining for lung immunoglobulins-Lung tissue collected at necropsy was stored at $-70^{\circ} \mathrm{C}$. Sections were cut on a cryostat and mounted on glass slides. Endogenous peroxidase was blocked with $1.6 \%$ hydrogen peroxide in absolute methanol for 20 minutes. $\mathrm{Fc}$ receptors were blocked with normal horse serum diluted $1 / 50$ in isotonic saline for 20 minutes. Antihuman IgG (HB-60) and antihuman IgM (HB-57) were obtained from American Type Culture Collection, Maryland, and used as neat supernatant. The IgA monoclonal antibody $(\mathrm{H}-1 \mathrm{l})$ is reactive with human IgA secretory component. It was supplied as ascites and diluted 1/50 for use. The antibodies were

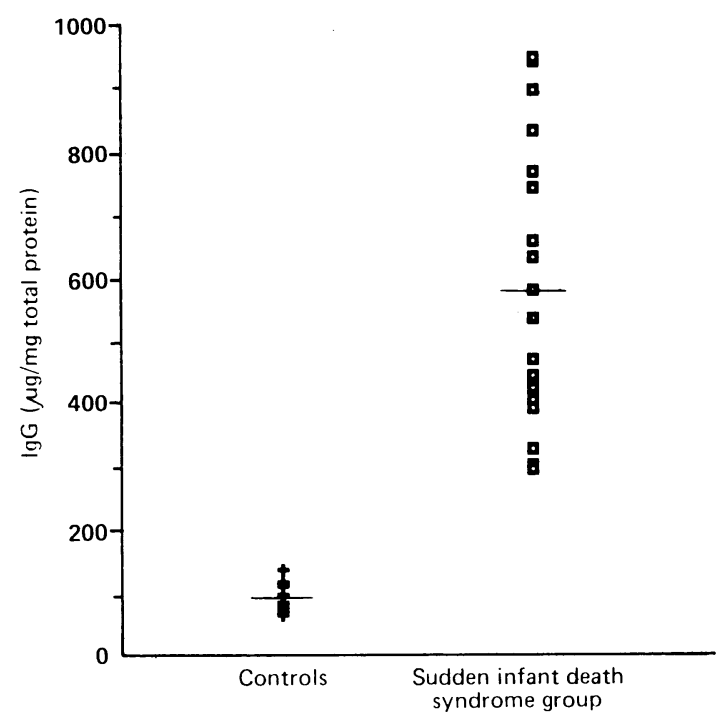

FIG 1-Pulmonary lavage fluid concentrations of IgG (expressed as $\mu \mathrm{g} / \mathrm{mg}$ total protein) in eight controls and 16 victims of sudden infant death syndrome. Roughly half of lavage fluid protein in sudden infant death syndrome group was IgG applied for two hours, followed by the secondary antibody (horse antimouse IgG-biotin conjugate) for 30 minutes. Avidin-Biotin complex (Vector Laboratories) was applied for one hour and the complex developed with $0.05 \%$ diaminobenzidine hydrochloride (Sigma Chemicals) and $0.01 \%$ hydrogen peroxide for 10 minutes. Nuclei were counterstained with Mayers progressive haematoxylin for $\mathbf{3 0}$ seconds. All incubation steps were performed at room temperature, with the sections washed three times in TRIS hydrochloric acid buffer $0.05 \mathrm{~mol} / 1 \mathrm{pH} 7.6$ between each step. Positive cells on immunohistological staining were identified by two observers through a double headed Olympus microscope with a $\times 25$ objective. On average 20 fields were studied per specimen. Results were expressed as the total number of positive cells per field divided by the number of fields studied and multiplied by 100 .

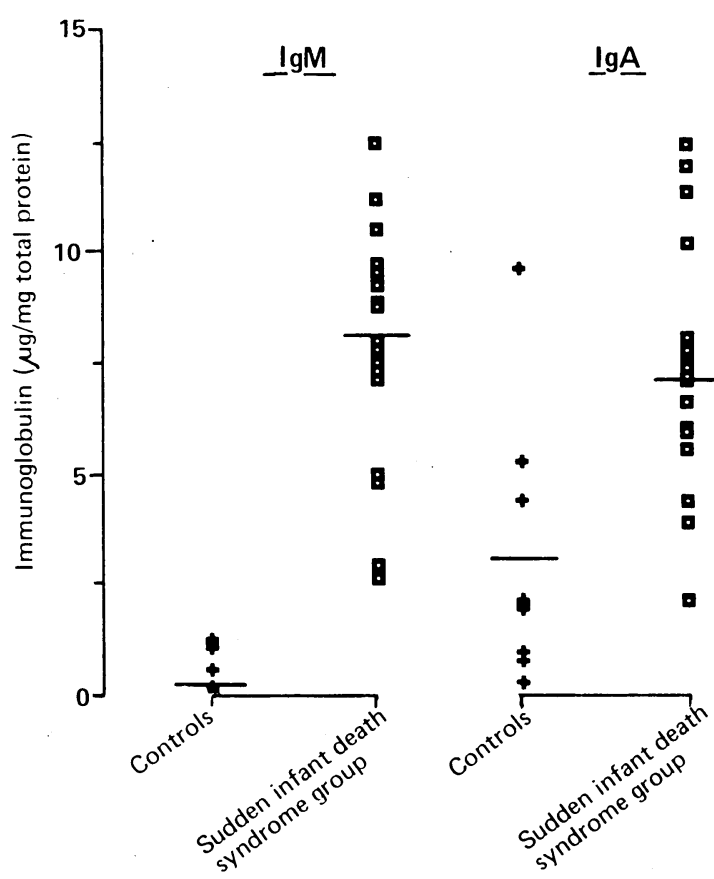

FIG 2-Pulmonary lavage fluid concentrations of IgM and IgA in eight controls and 16 victims of sudden infant death syndrome. There was significantly more of both immunoglobulins in victims of sudden infant death syndrome than controls

Statistics-Results are expressed as the mean and one standard deviation (1SD). As the immunoglobulin results did not conform to a normal distribution, the Mann-Whitney $\mathrm{U}$ test was used to compare values between the sudden infant death syndrome and control groups.

\section{Results}

Lung lavage samples - IgG was present in the lavage samples of all subjects, with remarkably high values in the sudden infant death syndrome group; just over half the total protein in the lavage samples was IgG (fig 1). The mean IgG concentration in the sudden infant death syndrome group was $578(216) \mu \mathrm{g} / \mathrm{mg}$ total protein and in the controls $93(22) \mu \mathrm{g} / \mathrm{mg}(\mathrm{p}<0.005)$. IgA and IgM concentrations were similar and quantitatively much lower than the IgG concentrations. The mean IgA concentration in the lavage fluid in the sudden infant death syndrome group was 7 (2) $\mu \mathrm{g} / \mathrm{mg}$ total protein and in the controls $3(3) \mu \mathrm{g} / \mathrm{mg}(\mathrm{p}<0.005)$ (fig 2). The mean IgM concentration in the sudden infant death syndrome group was 8 (3) $\mu \mathrm{g} / \mathrm{mg}$ total protein and in the controls $0.5(0.4) \mu \mathrm{g} / \mathrm{mg}(\mathrm{p}<0.005)$ (fig 2). Protein concentrations in the lavage samples were not significantly different between the two groups 


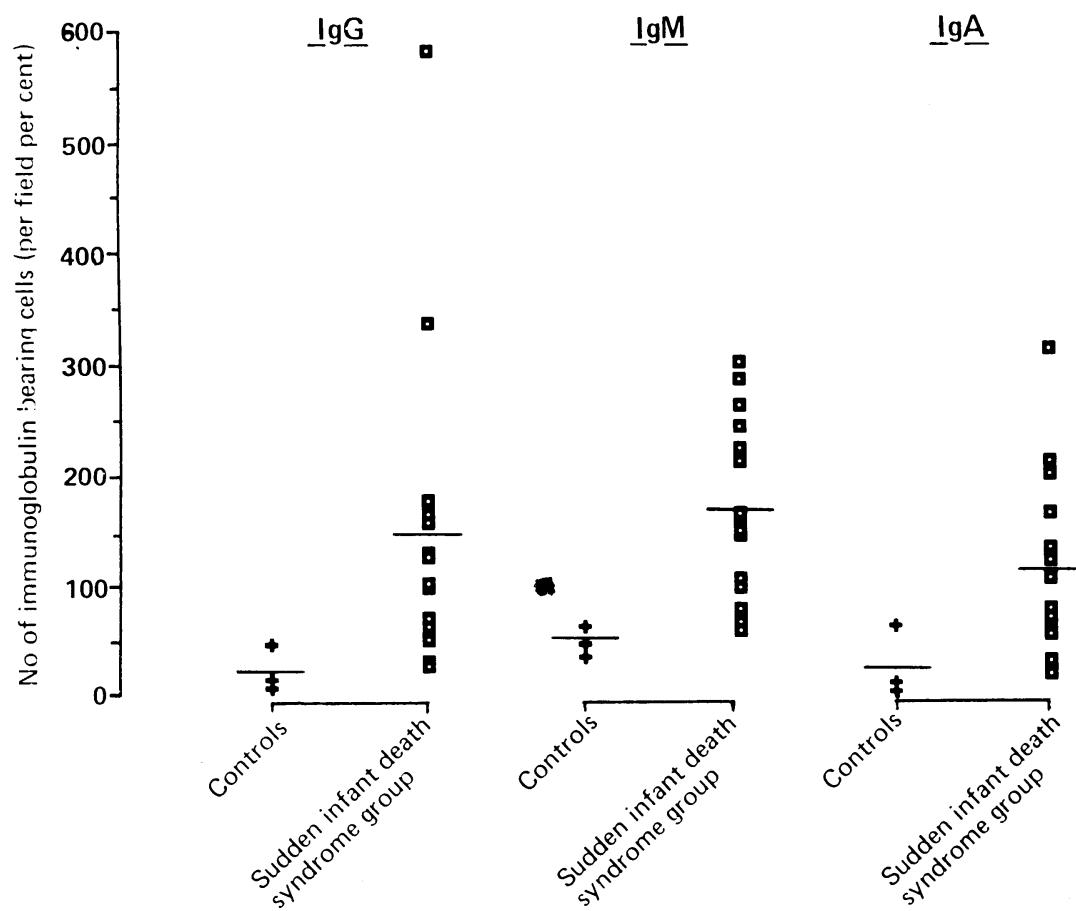

FIG 3-Numbers of positively stained (immunoglobulin bearing) cells per field per cent in frozen sections of lung tissue in four controls and 16 victims of sudden infant death syndrome. All three immunoglobulins were expressed more often in sudden infant death syndrome group

$(1.39(0.6) \mathrm{g} / \mathrm{l}$ in the sudden infant death syndrome group, $1 \cdot 54(1 \cdot 1) \mathrm{g} / \mathrm{l}$ in the controls).

Lung immunohistory - Positive cellular staining for immunoglobulins was evident in the terminal airways and alveolar interstitium and was extensive in victims of the sudden infant death syndrome (fig 3 ). The mean numbers of IgG positive cells on immunohistological staining expressed per field per cent were $151(140)$ in the sudden infant death syndrome group and 26 (16) in the controls $(p<0.005)$. For the IgA secretory component there were 119 (76) positive cells in the sudden infant death syndrome group and 29 (33) in the controls $(p<0.05)$. Similarly, for IgM there were 176 (78) positive cells in the sudden infant death syndrome group and $53(14)$ in the controls $(p<0.005)$. At the cellular level the staining pattern was diffuse, not granular, and distributed throughout the cytoplasm, not solely membrane staining. In general positive cells were diffuse throughout the section, though in a few sections in the sudden infant death syndrome group there were clumps of IgA or IgG positive cells around terminal airways. The staining suggested that they were plasma cells.

\section{Discussion}

In this paper we have shown by two separate methods (analysis of pulmonary lavage fluid and pulmonary immunohistological staining) that there is a difference in the amounts of immunoglobulin present in the lungs of children who have died of the sudden infant death syndrome compared with controls. The concentration of IgG in lavage fluid was very high and the number of pulmonary interstitial and terminal airway plasma cells that expressed IgG was increased in the sudden infant death syndrome. In addition, in comparison with the controls over half the lavage fluid protein was IgG, there was an increase in lavage fluid and cellular IgM, and there was a smaller but significant increase in the IgA secretory component. These differences were apparent whether the lavage fluid immunoglobulin concentration was expressed as $\mu \mathrm{g}$ immunoglobulin/mg total protein or mg immunoglobulin/ml lavage fluid (data not shown).
In a recent study by our group of respiratory tract immunoglobulins from ventilated neonates IgG was found to be the predominant immunoglobulin. ${ }^{9}$ In this series victims of the sudden infant death syndrome were on average one month younger than the controls. Data on lower respiratory tract immunoglobulin concentrations in normal children are not available. Concentrations in the serum and lower respiratory tract of intubated neonates, however, suggest a decline in IgG values with increasing age and a slow increase in IgA and IgM. ${ }^{9}$ These differences are not significant over one month.

Previous work also by our group on lung lavage cell phenotype in the sudden infant death syndrome has shown a difference between victims of the syndrome and controls. ${ }^{6}$ The relevance of this difference (lack of CD14A reactivity in the sudden infant death syndrome group) is uncertain but it is compatible with cellular activation ( $\mathrm{N}$ Hogg (London), personal communication).

There has been little work on pulmonary immune mechanisms in the sudden infant death syndrome. A study by Ogra et al in 1975 using a qualitative (radial gel diffusion) rather than quantitative method showed IgG and IgM to be present in lavage fluid in the sudden infant death syndrome, but secretory component to be absent in pulmonary tissue. ${ }^{10}$ Ackermann et al, in agreement with our findings, detected significantly increased IgG expression in pulmonary tissue from victims of the syndrome with a fluorescein labelled sheep antihuman IgG antibody. ${ }^{11} 12$

Our studies suggest that there is altered immunological function in the sudden infant death syndrome. There is alteration of cellular phenotypes and a gross increase in IgG and IgM concentrations in lung lavage fluid. The relevance of these changes is not clear. Possibly an unrecognised respiratory pathogen is stimulating high immunoglobulin concentrations in the respiratory tract. More probably, however, a dysregulation of immunoglobulin production stimulated by a trivial infection might serve to "trigger" the attack in an infant at risk by exposing antigens or modulating the immune response. ${ }^{13}$ It has been postulated, for example, that the sudden infant death syndrome may be a modified form of local anaphylaxis occurring in the lungs, possibly mediated by $\operatorname{IgG}^{14}$; infection might produce or expose the appropriate antigen for this type of reaction in susceptible children.

Though extravasation of IgG might be due to an anaphylactoid type of reaction, this could not account for the numbers of plasma cells seen in tissues where they are rarely if ever present. This finding points to local production of immunoglobulin. The evidence, both epidemiological and from this study, suggests that the respiratory tract is the prime target organ in the sudden infant death syndrome. Further investigation of pulmonary immunological responses is required.

This work was supported by the Sudden Infant Death Research Foundation of South Australia. We are grateful to A Hohmann, of Flinders Medical Centre, for the gift of IgA monoclonal antibody (H-11).

1 Kelly DH, Shannon DC. Sudden infant death syndrome and near sudden infant death syndrome: a review of the literature, 1964 to 1982. Pediatr Clin North Am 1982;29:1241-61

2 Beal SM. Sudden infant death syndrome: epidemiological comparisons between South Australia and communities with a different incidence. Aust Paediatr $\mathcal{1} 1986.22$ (suppl 1$): 13-6$

3 Uren EC, Williams AL, Jack I, Rees JW. Association of respiratory virus infections with sudden infant death syndrome. Med 7 A ust 1980;i:417-9.

4 Richards IDG, McIntosh HT. Confidential inquiry into 226 consecutive infant deaths. Arch Dis Child 1972;47:697-706.

5 Scott DJ, Gardner PS, McQuillan J, Stanton AN, Downham MAPS. Respiratory viruses and cot death. BrMed $\mathcal{F}$ 1978;ii:12-3.

6 Forsyth KD, Bradley J, Weeks S, Smith M, Skinner J, Zola H. Immunocyto logic characterization using monoclonal antibodies of lung lavage cell phenotype in infants who have died from SIDS. Pediatr Res 1988;23:187-90. 
7 Smart IJ, Koh LY. Competitive inhibition enzyme immunoassays for the measurement of human IgG, IgA, and IgM. F Immunol Methods 1983;60 329-39.

8 Lowry OH, Rosebrough NJ, Farr AL, Randall RJ. Protein measurement with the folin phenol reagent. I Biol Chem 1951;193:265-75.

9 Forsyth $\mathrm{KD}$, Koh L, Lawrence A, Bradley J. Immunoglobulin profile of tracheal aspirate fluid in intubated children. Clin Exp Immunol 1988;71: $357-61$

10 Ogra PL, Ogra SS, Coppola PR. Secretory component and sudden infant death syndrome. Lancet 1975; ii: 387-90.

11 Ackermann WW, Eveland WC, Maverakis NH, Raven C, Golden A. Bound immunoglobulin and foreign antigen in lungs of sudden infant death syndrome victims. Infect Immun 1979;24:925-31.

12 Raven C, Maverakis NH, Eveland WC, Ackermann Ww. The sudden infan death syndrome: a possible hypersensitivity reaction determined by distribution of IgG in lungs. F Forensic Sci 1978;23:116-28.

13 Valdes-Dapena MA. Sudden infant death syndrome: a review of the medical literature. Pediatrics 1980;66:597-614.

14 Coombs RRA, McLaughlan P. The enigma of cot death: is the modified anaphylaxis hypothesis an explanation for some cases? Lancet 1982;i:1388-9.

(Accepted 4 November 1988)

\section{Serious eye injuries due to war games}

\section{J F Acheson, M F P Griffiths, R J Cooling}

Accident and Emergency Department and Primary Care Clinic, Moorfields Eye Hospital, London EC1 2PD

J F Acheson, FRCS, registrar in ophthalmology

M F P Griffiths, FRCs, locum senior registrar in

ophthalmology

R J Cooling, FRCS, consultant ophthalmic surgeon

Correspondence to: $\mathrm{Mr} \mathrm{J} \mathrm{F}$

Acheson, Western

Ophthalmic Hospital,

London NW1.

Br.Med f 1989;298:26.
"War games" are an outdoor activity combining recreation, military style manoeuvres, and fantasy. Combatants in the games fire gelatin pellets filled with dye at each other from powerful air guns. War games' weaponry developed from paint guns used by forestry workers to mark trees for felling. These guns are powered either by carbon dioxide cartridges or by rounds detonated by percussion. Gas cartridge weapons are not classified as firearms in the United Kingdom, in contrast to rounds detonated by percussion. The ammunition comprises pellets filled with paint, and the guns are remarkably realistic, resembling revolvers, semiautomatic handguns, rifles, or machine pistols. Muzzle velocities of up to $134 \mathrm{~m} / \mathrm{s}$ and energies of $10 \mathrm{~J}$ are possible with rates of fire of 1200 rounds a minute. Combatants are issued with protective goggles, and shots aimed at the head are prohibited.

\section{Case reports}

Although goggles should be worn and the head avoided, during July 1987 to February 1988 we saw six cases of serious ocular injury resulting from war games. The table summarises these cases.

\section{Comment}

Serious injuries due to war games were first reported in Canada in 1984..$^{23}$ To our knowledge they have not been reported in Britain, presumably because this new pastime is not yet so popular in this country. Easterbrook et al reviewed data collected by the eye safety committee of the Canadian Society of Ophthalmology and described 26 cases, including one of a ruptured eve, which was eventually excised. ${ }^{2}$ They noted that though eyeguards had been provided in all instances, none were in use at the time of injury. Subsequently two isolated cases were reported from the United States $^{+\varsigma}$; in one goggles were being worn but did not prevent hyphaema, vitreous haemorrhage, and a retinal tear. ${ }^{5}$

Goggles were supplied to all our six patients; a lens from one pair, however, dropped out spontaneously, and in three cases the goggles were removed for extra comfort and visibility before injury. In the remaining two patients who were wearing goggles both injuries resulted from the plastic pellet dislocating the lens from the frame and driving it on to the eye. The toughened protective glasses and rubber rimmed industrial goggles were inadequate, and single piece polycarbonate eye protectors such as those recommended for racket sports seem more suitable.

The injuries reported were of a blunt, non-penetrating type normally associated with fairly low kinetic energies further dissipated by goggles, when worn. Permanent visual loss, however, may result from these games as the weapons have sufficient muzzle velocities to cause penetration of the eye. Moreover, though the retained subconjunctival dye in case 4 did not seem to be toxic, blunt ocular injury carries considerable morbidity. Emergency admission to hospital was required in three of our six cases to treat raised intraocular pressure and to minimise the risk of rebleeding hyphaema. All six patients required prolonged follow up to identify and treat delayed complications such as secondary glaucoma, contusion cataract, recurrent corneal erosion syndrome, retinal pigment epithelial degeneration, and retinal detachment.

We gratefully acknowledge the help of Mr D Pryor, Metropolitan police laboratory, firearms section

1 Warner K, ed. Gun digest catalogue. 42nd ed. Illinois: BBI Books Inc, 1988: 416-7.

2 Easterbrook M, Pashby TJ. Eye injuries associated with war games. Can Med Assoc f 1985;133:415-7.

3 Tardif D, Little J, Mercier M, Podtenenev M, Labelle P. Ocular trauma in war games. Physician and Sports Medicine 1986; 14:91-4.

games. Physician and Sports Medicine 1986;14:91-4.
4 Ryan EH, Lissner G. Eye injuries during "war games." Arch Ophthalmol 1986; 104:1435-6.

5 Martin PL, Magolan JJ. Eye injury during "war games" despite the use of goggles; case report. Arch Ophthalmol 1987;105:321-2.

(Accepted 26 September 1988

Details of six cases of ocular injury due to weapons used in war games

\begin{tabular}{|c|c|c|c|c|c|c|}
\hline $\begin{array}{l}\text { Case } \\
\text { No }\end{array}$ & $\begin{array}{c}\text { Age } \\
\text { (years) }\end{array}$ & $\begin{array}{l}\text { Wearing } \\
\text { goggles }\end{array}$ & $\begin{array}{l}\text { Emergency } \\
\text { admission } \\
\text { to hospital }\end{array}$ & $\begin{array}{l}\text { Initial } \\
\text { visual } \\
\text { acuity }\end{array}$ & Presentation & $\begin{array}{l}\text { Final visual acuity } \\
\text { (months later) }\end{array}$ \\
\hline 1 & 16 & No & Yes & $\begin{array}{c}\text { Hand } \\
\text { movements }\end{array}$ & $\begin{array}{l}\text { Corneal abrasion, hyphaema, contusion cataract, } \\
\text { contusion of retina, and subsequent atrophy of } \\
\text { retinal pigment epithelium }\end{array}$ & $\begin{array}{l}6 / 12 \text { (Six months; after } \\
\text { extraction of cataract and } \\
\text { insertion of aphakic contact } \\
\text { lens) }\end{array}$ \\
\hline 2 & 35 & Yes & Yes & $6 / 12$ & $\begin{array}{l}\text { Conjunctival laceration, hyphaema, drainage angle } \\
\text { recession, rupture of iris sphincter, and contusion } \\
\text { of retina }\end{array}$ & \\
\hline 3 & 28 & Yes & No & $6 / 6$ & Hyphaema, corneal abrasion & 6/6 (Two months) \\
\hline 4 & 38 & No & Yes & $6 / 24$ & $\begin{array}{l}\text { Conjunctival laceration, retained subconjunctival } \\
\text { vegetable dye, corneal abrasion, hyphaema, } \\
\text { rupture of iris sphincter, vitreous haemorrhage, } \\
\text { contusion of retina, atrophy of retinal pigment } \\
\text { epithelium }\end{array}$ & $6 / 12$ (Three months) \\
\hline 5 & 24 & No & No & $6 / 5$ & $\begin{array}{l}\text { Hyphaema, transient raised intraocular pressure, } \\
\text { vitreous haemorrhage, retinal tear (treated by } \\
\text { cryopexy) }\end{array}$ & $6 / 6$ (Three months) \\
\hline 6 & 19 & No & No & $6 / 5$ & Hyphaema, drainage angle recession & $6 / 5$ (One month) \\
\hline
\end{tabular}

